\title{
Peculiarities of behaviour of taiga (Ixodes persulcatus) and sheep (Ixodes ricinus) ticks (Acarina: Ixodidae) determined by different methods
}

\author{
Andrey N. Alekseev ${ }^{1}$, Per M. Jensen ${ }^{2}$, Helen V. Dubinina ${ }^{1}$, Lioubov A. Smirnova ${ }^{2}$, Natalia A. Makrouchina ${ }^{2}$ \\ and Sergey D. Zharkov ${ }^{2}$ \\ ${ }^{1}$ Zoological Institute, Russian Academy of Sciences, Universitetskaya nab. 1, 199034 St. Petersburg, Russia; \\ ${ }^{2}$ Zoology Section, Department of Ecology, The Royal Veterinary and Agricultural University, Thorvaldsensvej 40, 1871 \\ Frederiksberg C, Denmark
}

Key words: tick, Borrelia, locomotor activity, questing, exoskeleton anomalies

\begin{abstract}
A comparison of the behavioural peculiarities of Ixodes persulcatus Schulze, 1930 (north-western population, Russia) and Ixodes ricinus (L., 1758) from western Russia and Denmark was determined by using two methods. Method 1 involved a sojourn of ticks on vertical plastic sticks and showed that the questing behaviour of I. ricinus nymphs was dependent on temperature and relative humidity (RH). A significantly greater number of nymphs quested at $22^{\circ} \mathrm{C}$ and $100 \% \mathrm{RH}$ than at $18^{\circ} \mathrm{C}$. When the humidity was reduced to $30 \%$ all of the nymphs departed. In the second method, the activity of ticks on an inclined "ticksdrome" was estimated. The activity of I. ricinus adults from the Danish population was 1.2 times greater than that of ticks from Russia. Females of the species studied and specimens from all study areas were more active than all other stages of development. The locomotor activity of both adult and immature I. ricinus that were infected with Borrelia burgdorferi sensu lato was suppressed when compared with uninfected specimens. The locomotor activity of I. persulcatus females infected by borreliae with exoskeleton anomalies was 1.3 times greater $(\mathrm{P}<0.05)$ than that of infected ticks without anomalies. Our data showed that infected females with exoskeleton anomalies could crawl faster on a human and reach uncovered parts of the body that are vulnerable for attachment and feeding. A study of locomotor activity and questing behaviour may be useful for comparing the risk for different tick species and populations to transmit tick-borne pathogens.
\end{abstract}

Successful transmission of pathogens to humans depends on the behaviour of the vectors inclusive of their activity, mobility, and ability to quest for prey and attack hosts. Ixodid ticks of different species and populations within species differ in their abilities to transmit pathogens and for successful maintenance of disease foci. For example, the ticks Ixodes persulcatus Schulze, 1930, are more effective vectors of pathogens than Ixodes ricinus (L., 1758) (Alekseev and Dubinina 1994, Kovalevskii and Korenberg 1995). Methods used to estimate tick behaviour vary and are generally directed to ascertain locomotor activity, which implies an orientation to physical parameters of the environment such as relative humidity, temperature and light and behaviour during questing for a host.

The predominant behaviour of $I$. ricinus is the tendency of the tick to ascend vegetation during the day and descend at night (McLeod 1935, Lees and Milne 1951, Arthur 1962). A general survey of unfed $I$. persulcatus was given by Babenko (1985) and Babenko et al. (1985). However the work of Okulova (1978) may be the most interesting example of the orientation behaviour of unfed ticks as related to the physical parameters. Okulova (1978) has presented data on the vertical and horizontal movements of questing taiga ticks, which were studied in a forest environment under naturally occurring temperature and relative humidity. Adults climbed up the aconite and fern stems to a maximum height of $80 \mathrm{~cm}$ when the temperature $23.3^{\circ} \mathrm{C}$. According to the observations of Filippova (1977) some of $I$. persulcatus specimens in Primorye (Russian Far East) climb to a height of $2 \mathrm{~m}$. Browning (1976) studied tick questing behaviour, by placing ticks of the genus Rhipicephalus on vertical sticks. Lefcort and Durden (1996) also used sticks to study the behaviour of Ixodes scapularis Say, 1821 nymphs and adults, and compared specimens that were infected in the laboratory by Borrelia burgdorferi sensu stricto to uninfected ticks. In addition, I. persulcatus adults infected with Borrelia burgdorferi sensu lato were less active than those that were uninfected (Alekseev and Dubinina 1994, Alekseev 1996, Alekseev et al. 1996).

Our research was conducted to compare the behaviour of the different stages of $I$. ricinus that belonged to two different European populations of this species in North Zealand (Denmark) and Curonian Spit (Kaliningrad region, Russia). In addition, the locomotor characteristics of larvae and nymphs of I. ricinus and I. persulcatus versus adults were compared.

The main purpose of the study was to determine differences in the behaviour of two species of ticks that belong to the different geographic regions. We also 
tested a hypothesis that the locomotor activity of ticks changes when the vector is under the influence of Borrelia infection. In addition, we wanted to determine the effects of infection on uninfected I. persulcatus and on the specimens that had abnormal exoskeletons.

\section{MATERIALS AND METHODS}

Two species of ticks and three allopatric populations were used in the experiments. Ixodes persulcatus ticks were collected from April to July, 1996 in the vicinity of St. Petersburg (Russia) and I. ricinus were collected from August to September, 1997 and 1998, on the Curonian Spit of the Kaliningrad region of the Russian enclave and in October, 1997, in Grib Skov (North Zealand, 80 km from Copenhagen, Denmark). All ticks in Russia were collected by flagging, placed into wet gauze bandage, transferred to the laboratory, and sorted using a stereomicroscope to determine their stage, sex and exoskeleton structure. Adults collected from the heavy metal polluted area of St. Petersburg had crater-like depressions, a crumpled female scutum, and different kinds of female scutum dents on their exoskeleton, and sometimes, undeveloped palps (Alekseev and Dubinina 1993).

The tick deformations (Alekseev and Dubinina 1993), caused most probably by the action of heavy metal ions (Alekseev and Dubinina 1996a), were called anomalies. All ticks collected in Russia were sorted and placed in selected humidity-gradient glass tubes (Alekseev and Dubinina 1996b). In the tubes the ticks were able to select a location that had their desired relative humidity that ranged from $98 \%$ near the wet bottom to $45-50 \%$ near the cotton plug. In Denmark the ticks were also collected by flagging, but they were removed from the flag by a small vacuum suction device and then placed into $4 \mathrm{~cm}$ in diameter plastic Petri dishes. No more than 20-25 larvae or nymphs and 10-12 adults were put into each dish. Dishes with ticks were maintained in plastic boxes with a $1 \times 1 \mathrm{~cm}$ piece of damp paper in darkness for a minimum $2 \mathrm{wk}$ before they were used in experiments. After completion of the behavioural experiments most of ticks were screened for natural infection with $B$. burgdorferi s.l. by darkfield microscopy and/or IFA analysis using polyclonal antibodies and fluorescent microscopy.

Two methods were used for estimating tick behaviour. The first method represented a modification of using sticks described by Browning (1976). A thick piece of polyethylene foam was put into a $10 \times 25 \times 45 \mathrm{~cm}$ plastic box and $3 \times 3 \mathrm{~mm}, 25$ $\mathrm{cm}$ long plastic straws were pushed vertically into it. The polyethylene foam was either kept dry or immersed in water up to a height of $3 \mathrm{~cm}$ from the sticks' bases. Experiments were carried out at temperatures of 18,22 and $24^{\circ} \mathrm{C}$. Nymphs and larvae were maintained in darkness under $100 \%$ humidity until the beginning of the experiment. One group of ticks was illuminated for $1 \mathrm{~h}$ directly before the beginning of the experiment and another group was tested just after being kept in darkness. The ticks were placed on the plastic sticks $2-3 \mathrm{~cm}$ above the surface of the dry foam or the water level. Experimental conditions permitted nymphs either to stay in place or to move either up or down the stick. The percentage of ticks remaining on the sticks was determined and an

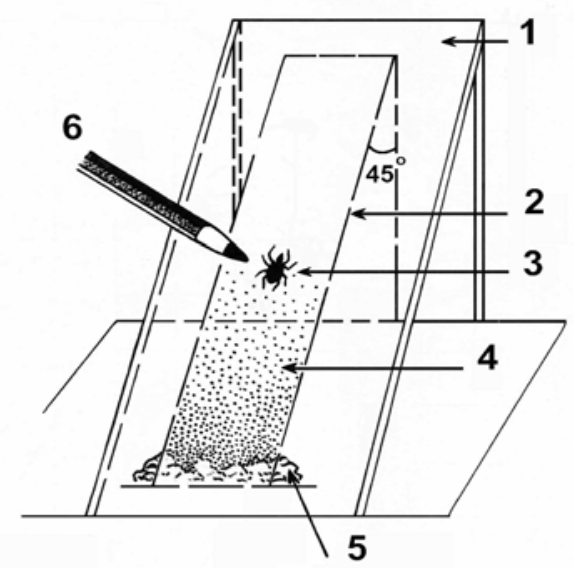

Fig. 1. Scheme of ticksdrome. 1 - glass screen and transparency; 2 - calico strip (ticksdrome); 3 - tick; 4 - wet surface of the strip; 5 - wet cotton wool; 6 - pen.

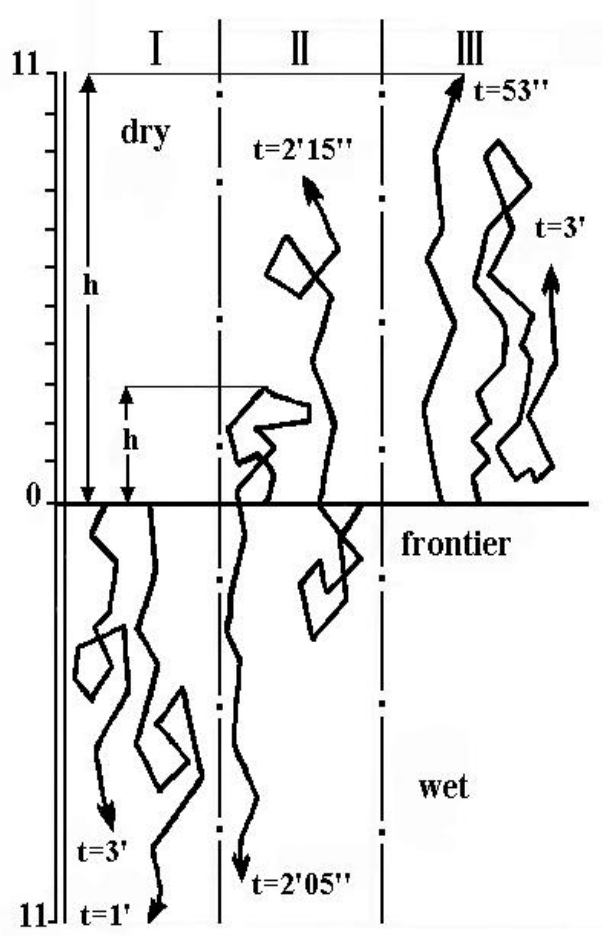

Fig. 2. Examples of tick tracks on ticksdrome. I - only down the wet surface; II - up and down on dry and wet surfaces; III - only up on dry surface.

average rate of climb was calculated after $4 \mathrm{~h}$ from the beginning of the experiment. 
The second method consisted of studying tick activity on an inclined $\left(45^{\circ}\right)$ surface of a ticksdrome (Fig. 1). This device (Alekseev 1996, Alekseev et al. 1996) was made of a white (3 $\mathrm{cm}$ wide, $22 \mathrm{~cm}$ long) tight calico strip with a dry upper half and periodically moistened lower part (Fig. 1). Tracks, which mirrored the route followed by the ticks, was made by pen on transparency and permitted the measurement of the speed, height and other parameters involved in tick locomotor activity during $3 \mathrm{~min}$ of testing. Examples of the types of tick movement is shown in Fig. 2. A locomotor activity index (LAI) was calculated for each specimen using the modified equation (1) published by Alekseev (1996):

$$
\mathrm{LAI}=\mathrm{s} / \mathrm{s}^{\prime}+\mathrm{h} / \mathrm{h}^{\prime}+\mathrm{wa}+\mathrm{wb}-\mathrm{m} / \mathrm{m}^{\prime}-\mathrm{f} / \mathrm{f}^{\prime}
$$

[s - speed $(\mathrm{cm} / \mathrm{min}) ; \mathrm{s}^{\prime}=1 \mathrm{~cm} / \mathrm{min} ; \mathrm{h}$ - height of tick movement $(\mathrm{cm}) ; h^{\prime}=1 \mathrm{~cm}$; wa - portion of the upward path relative to the total path; wb - portion of the path above the humidity gradient; $\mathrm{m}$ - meander, the number of turns to the length of the path; $m$ ' $=1$ number of turn to the length of the path; $f$ - number of falls from or on the ticksdrome surface; $f^{\prime}=1$ fall from or on the ticksdrome surface].

Mean locomotor activity of the group (LAI') of the different stages and sexes of the normal and anomalous uninfected and infected ticks was calculated using another equation (2):

$$
\mathrm{LAI}^{\prime}=\mathrm{K}_{1}(\mathrm{~S} / \sigma)^{2}+(\mathrm{H} / \sigma)^{2}+(\mathrm{WA} / \sigma)^{2}+(\mathrm{WB} / \sigma)^{2}-\mathrm{K}_{2}(\mathrm{M} / \sigma)^{2}
$$
$-\mathrm{K}_{3}(\mathrm{~F} / \sigma)^{2}$

$[\mathrm{S} / \sigma-$ mean value of speed divided by standard deviation; $\mathrm{H} / \sigma-$ same for height etc (see equation 1 ); $\mathrm{K}_{1}=2 ; \mathrm{K}_{2}=0.5$; $\left.\mathrm{K}_{3}=10\right]$.

Experiments were carried out at $21-22^{\circ} \mathrm{C}, 38-40 \% \mathrm{RH}$, and an illumination of about $500 \mathrm{~lx}$.

A total of 2,070 nymphs were used in the experiments for determining the questing activity of $I$. ricinus and a total of 612 specimens were used to compare the activity of Borreliainfected and uninfected larvae, nymphs and adults of I. ricinus obtained in Denmark and Russia (152 larvae, 187 nymphs and 273 adults). We used 1,091 specimens for comparing the activity of different stages of development of uninfected $I$. ricinus and I. persulcatus (Fig. 4). We compared 74 females of Borrelia-infected I. persulcatus with (20) and without (54) anomalies of their exoskeleton. Statistical analysis of the differences in the questing behaviour of ticks under different conditions and in the activity of the infected and uninfected specimens of different populations of I. ricinus was done using the t-test (Wilkinson 1990).

\section{RESULTS}

\section{Estimation of questing behaviour}

Only $10 \%$ of the Ixodes ricinus nymphs (Danish) that were held at $20^{\circ} \mathrm{C}$ and constant illumination continued questing when the $\mathrm{RH}$ was $30 \%$ but $50 \%$ of these nymphs continued questing when the humidity was $100 \%$. Only one-tenth of the initial number of nymphs continued questing in dry conditions, whereas more than $50 \%$ of the nymphs placed above the water layer continued questing (Fig. 3). The difference was statistically significant $(\mathrm{P}<0.001)$. Temperature influenced the length of time that the ticks were questing (Fig. 4). The number of the ticks remaining on

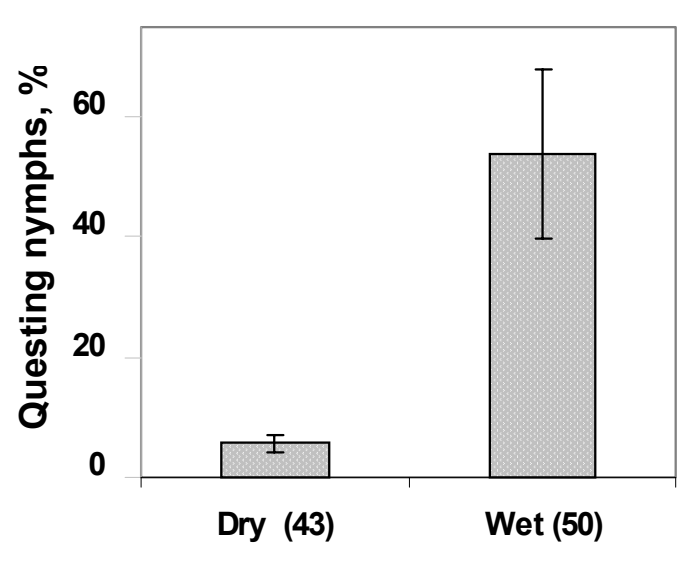

Foam characteristic

Fig. 3. Questing behaviour of Ixodes ricinus nymphs at different relative humidities. In parentheses, No. of tested nymphs; error bars, S.D.

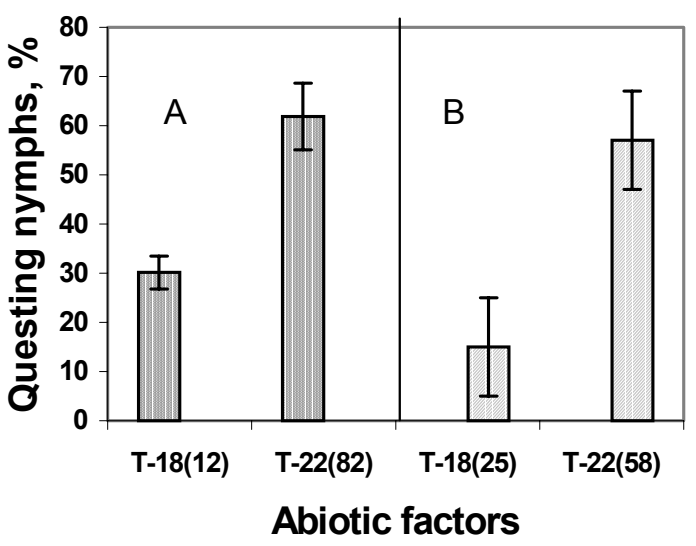

Fig. 4. Questing behaviour of Ixodes ricinus nymphs at different temperatures after their transfer from the darkness to light. A - nymphs transferred to sticks from darkness after $1 \mathrm{~h}$ exposure to light; $\mathbf{B}$ - nymphs transferred to sticks from darkness immediately; T-18, T-22 - temperature $\left({ }^{\circ} \mathrm{C}\right)$. In parentheses, No. of tested nymphs; error bars, S.D.

the sticks maintained at $22^{\circ} \mathrm{C}$ was $2-3$ times greater than at $18^{\circ} \mathrm{C} \quad(\mathrm{A}: \mathrm{P}<0.01 ; \mathrm{B}: \mathrm{P}<0.081)$. Before the experiments one group of ticks was exposed to $1 \mathrm{~h}$ of illumination. Another group was transferred from darkness to light immediately. During the experiments, a decrease in the number of ticks on sticks was observed. Decrease was different in the tested groups. However, $4 \mathrm{~h}$ later, this difference was not statistically significant and the number of ticks on the sticks depended on temperature alone. 


\section{Active behaviour}

The low level of natural infection in the larvae and nymphs made comparisons of infected tick activity for these stages difficult. Nevertheless, the LAI of infected larvae from Russia were 2.35-2.51 times $(\mathrm{P}<0.05)$ and those from Denmark 11.2 times $(\mathrm{P}<0.001)$ less than the LAI of uninfected larvae (Table 1). Nymphs infected with borreliae collected in Russia also had a lower LAI when compared with uninfected ticks. The differences in LAI were found to be very small but significant (1.44 and $1.88, \mathrm{P}<0.01)$. No infected specimens were found among nymphs that were collected in Denmark, in October 1997, but the LAI of uninfected nymphs from the Danish population was approximately 2 times more than that of the uninfected nymphs from the Russian population. Comparison of the LAI of Borrelia-infected nymphs from the Russian population with uninfected specimens from Denmark showed differences of 2.6-4 times. The LAI of Borrelia-infected adults collected in Denmark was also lower (6.53 times) than the LAI of uninfected ticks. Activity indexes of infected adults, collected in Russia, were lower than that of uninfected specimens. The differences were not great (1.36 and $1.25)$, but statistically significant $(\mathrm{P}<0.05)$. In all experiments, the locomotor activity index of all $I$. ricinus stages was lower among infected specimens than among uninfected ticks. This difference was found to be greater among ticks that had been collected in Denmark. Also, uninfected nymphs and larvae collected in Denmark had greater LAI than those from Russia (LAI of larvae was 1.2 times, LAI of nymphs was 1.8 times greater).

The use of the inclined ticksdrome gave us an opportunity to compare the speed, ascendant height, meandering and the entire activity of different tick stages that belonged to two allopatric populations of $I$. ricinus (Fig. 5A, B) and I. persulcatus (Fig. 5C). We confirmed that different stages of ticks moved differently.

Nymphs of both populations of I. ricinus were more active than larvae. Females moved more quickly and were more active than males. The highest index of meandering occurred in larvae. We noted that nymphs collected in Denmark in comparison with adults climbed to a lower height (1.1 times), but that the nymphs collected in Russia (both $I$. ricinus and $I$. persulcatus) climbed to a height only $1 / 2$ that of adults. The LAI was larger in all phases of development for ticks of the Danish population of I. ricinus when compared with $I$. ricinus ticks collected in Russia. The activity parameters of I. persulcatus ticks were greater than that of $I$. ricinus. The LAI was twice that of the Russian I. ricinus index and one and a half times greater than the LAI of Danish I. ricinus (Fig. 5C). The presence of borreliae in $I$. ricinus tick suppressed the locomotor activity of all stages of their development (Table 1).
The same phenomenon had been previously observed for the normal adult I. persulcatus ticks by Alekseev and Dubinina (1994) and Alekseev (1996), but the presence of $B$. burgdorferi s.l. in the specimens with exoskeleton anomalies appeared to make I. persulcatusinfected specimens more active when compared with infected specimens having no anomalies (Fig. 6). Under the same meandering indexes, the entire locomotor activity indexes (LAI'), the speed of movement and the height of climbing above the humidity gradient were appreciably greater in the infected specimens with exoskeleton anomalies. The difference was statistically significant $(\mathrm{P}<0.05)$.

\section{DISCUSSION}

These studies on the questing and locomotor activity of ticks suggest the following conclusions. The questing behaviour of nymphs appeared to be dependent on the relative humidity and air temperature. The optimal conditions for questing $I$. ricinus nymphs above the water surface was $22^{\circ} \mathrm{C}$. The inclined ticksdrome successfully determined the locomotor activity of ticks and demonstrated the differences in the behaviour of the different species and stages of Borrelia-infected and uninfected specimens.

The comparison of activity of I. persulcatus and of I. ricinus that were collected in the north-western and western Russia (Fig. 5B, C) demonstrated that the entire locomotor activity (LAI) of $I$. persulcatus nymphs was 4 times and that of adults approximately 2 times as great as that of $I$. ricinus. Females of the populations used in this study were more active than other stages of development. It is likely that the greater activity and "aggressiveness" of I. persulcatus ticks particularly the females, made them more competent as vectors of the agents of borreliosis when compared with I. ricinus. We also noted that nymphal activity in the Danish population of I. ricinus (Fig. 5A) was comparable with that of the adults. These data corresponded to the greater role of nymphs as vectors of borreliosis in Denmark reported by Jensen (1998), which was also correlated by a greater abundance of nymphs in comparison with adults.

We showed that the activity of infected I. ricinus larvae, nymphs and adults was less than that of uninfected ticks (Table 1). Most of the $I$. ricinus were infected by Borrelia afzelii (Alekseev et al. 1998), whereas I. scapularis in North America are reported to be infected with B. burgdorferi s.s. (Lefcort and Durden 1996). This difference could be the cause that they demonstrated a stimulating effect of B. burgdorferi s.s. on the activity of $I$. scapularis nymphs. Borreliae depressed the nymphal activity of $I$. ricinus and $I$. persulcatus (Table 1, Fig. 5A, B), but this does not exclude the possibility of their participation in borreliae transmission to humans. 


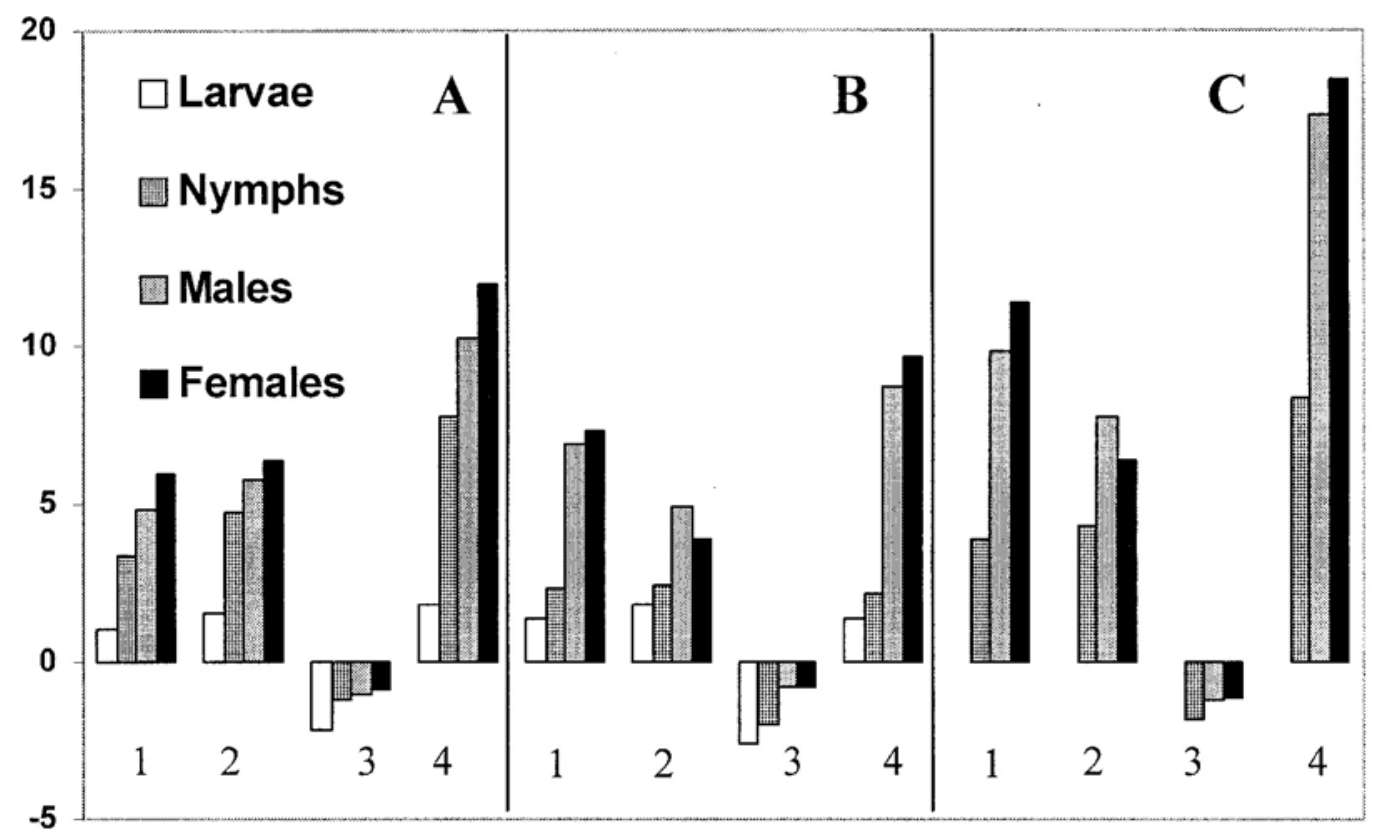

Fig. 5. Locomotor activity of different stages of uninfected Ixodes persulcatus and Ixodes ricinus ticks. Abscissa - parameters: 1 - speed, $\mathrm{cm} / \mathrm{min} ; 2$ - height, $\mathrm{cm} ; 3$ - meander, number of turns to the length of the path; 4 - locomotor activity index (LAI). Ordinate - values of parameters. A - I. ricinus from Grib Scov, North Zealand, Denmark (49 larvae, 51 nymphs, 31 adults); B - I. ricinus from Curonian Spit, Kaliningrad region, Russia (88 larvae, 277 nymphs, 276 adults); C - I. persulcatus from St. Petersburg vicinity, Russia (94 nymphs, 225 adults).

Table 1. Differences in the locomotor activity of Borrelia-infected and uninfected Ixodes ricinus ticks, collected in Denmark (1997) and Russia $(1997,1998)$. These tests were conducted using the ticksdrome.

\begin{tabular}{|c|c|c|c|c|c|c|c|c|}
\hline \multicolumn{3}{|c|}{ Tick characteristic } & \multirow{2}{*}{\multicolumn{2}{|c|}{ No. of tests }} & \multirow{2}{*}{\multicolumn{2}{|c|}{$\begin{array}{l}\text { Locomotor activity index } \\
\text { (LAI) values * }\end{array}$}} & \multirow{2}{*}{\multicolumn{2}{|c|}{ t-test, P }} \\
\hline \multirow{2}{*}{ Stage } & \multirow{2}{*}{ Place of collection } & \multirow{2}{*}{ Infection } & & & & & & \\
\hline & & & 1997 & 1998 & 1997 & 1998 & 1997 & 1998 \\
\hline \multirow{4}{*}{ Larvae } & \multirow{2}{*}{ Russia } & uninfected & 33 & 66 & $1.5 \pm 0.2$ & $2.3 \pm 0.2$ & \multirow{2}{*}{$<0.05$} & \multirow{2}{*}{-} \\
\hline & & infected & 2 & 1 & $0.7 \pm 0.4$ & 0.9 & & \\
\hline & \multirow{2}{*}{ Denmark } & uninfected & 49 & - & $1.8 \pm 0.3$ & - & \multirow{2}{*}{$<0.001$} & \multirow{2}{*}{ - } \\
\hline & & infected & 1 & - & 0.2 & - & & \\
\hline \multirow{4}{*}{ Nymphs } & \multirow{2}{*}{ Russia } & uninfected & 43 & 72 & $4.3 \pm 0.4$ & $3.6 \pm 0.3$ & \multirow{2}{*}{$<0.01$} & \multirow{2}{*}{$<0.01$} \\
\hline & & infected & 15 & 6 & $3.0 \pm 0.5$ & $1.9 \pm 0.4$ & & \\
\hline & \multirow{2}{*}{ Denmark } & uninfected & 51 & - & $7.8 \pm 0.6$ & - & \multirow{2}{*}{-} & \multirow{2}{*}{-} \\
\hline & & infected & 0 & - & - & - & & \\
\hline \multirow{4}{*}{ Adults } & \multirow{2}{*}{ Russia } & uninfected & 82 & 114 & $9.7 \pm 0.6$ & $12.3 \pm 0.5$ & \multirow{2}{*}{$<0.05$} & \multirow{2}{*}{$<0.05$} \\
\hline & & infected & 20 & 25 & $7.1 \pm 0.7$ & $9.8 \pm 0.8$ & & \\
\hline & \multirow{2}{*}{ Denmark } & uninfected & 31 & - & $11.8 \pm 1.3$ & - & \multirow{2}{*}{$<0.001$} & \multirow{2}{*}{-} \\
\hline & & infected & 1 & - & 1.8 & - & & \\
\hline
\end{tabular}

* Means \pm S.D.

Alekseev and Dubinina (1997) demonstrated that adults having exoskeleton anomalies and Borrelia infection moved more actively than ticks with normal morphology and with infection (Fig. 6). This phenomenon appeared to be associated with the consequences of the anthropogenic pressure and with environmental pollution, which caused the development of an I. persulcatus population with changed morphology (Alekseev and Dubinina 1993) and metabolism.

Those data do not mean that these specimens became more active under the influence of B. burgdorferi s.l. but, however, demonstrated that a lower suppression of activity was caused by the pathogen. Nevertheless, the data indicated that a greater danger of human contact 


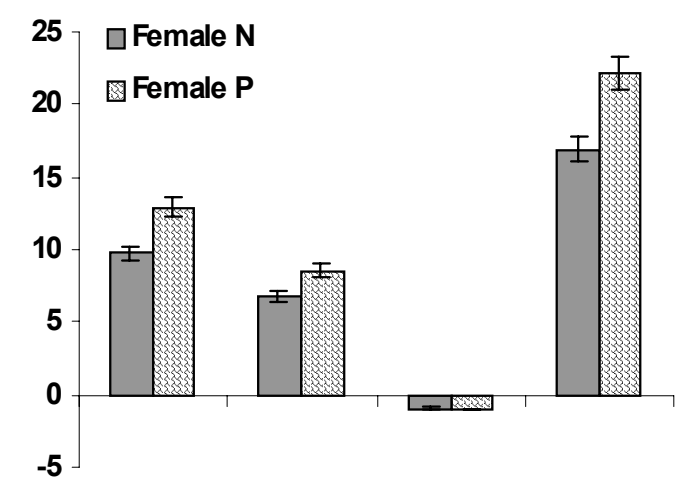

Speed Height Meander Activity

Fig. 6. Comparison of activity parameters of Borrelia-infected normal $(\mathrm{N})$ and abnormal $(\mathrm{P})$ Ixodes persulcatus females. Abscissa - parameters of locomotor activity; ordinate - values of parameters. Female $\mathrm{P}-$ specimens with exoskeleton abnormalities or pathology (20 ticks); Female $\mathrm{N}-$ specimens without them (54 ticks). Error bars, S.D. existed with these females that could result as a quicker attack on humans and the speed in which they reach open parts of the body that are vulnerable for attachment and feeding. It is clear that the accumulation of morphologically and biochemically changed specimens in the vector population increased the risk of pathogen transmission. Estimation of the activity parameters of ticks - vectors of borreliosis and other tick-borne diseases has both theoretical and practical importance. This shows the value of using tick activity comparisons with pathogen transmission risk for different species of ticks in different populations, and stages of development within these populations.

Acknowledgements. The authors wish thank to Prof. C.D. Steelman, Co-Editor of Journal of Medical Entomology (University of Arkansas, Fayetteville, USA) for the valuable advice and improvement of the English version of the manuscript. The research described in this paper was made possible in part by Grant 9600864 from Danish Research Councils, and in part by Grant N 98-04-49899 from the Russian Basic Research Foundation.

\section{REFERENCES}

ALEKSEEV A.N. 1996: Tick pathogen interactions: behaviour of infected and uninfected ticks (Ixodidae). In: R. Mitchell, D.J. Horn, G.R. Needham and W.C. Welbourn (Eds.), Acarology IX. Vol. 1. Proceedings. Ohio, Biol. Survey, Columbus, Ohio, pp. 113-115.

ALEKSEEV A.N., BURENKOVA L.A., VASILYEVA I.S., DUBININA H.V., CHUNIKHIN S.P. 1996: The functioning of mixed tick-borne infection foci in Russia. Med. Parazitol. Parazit. Bolezni 4: 9-16. (In Russian.)

ALEKSEEV A.N., DUBININA H.V. 1993: Abnormalities in Ixodes ticks (Ixodoidea, Ixodinae). Acarina. Russian J. Acarol. (Moscow) 1: 73-85.

ALEKSEEV A.N., DUBININA H.V. 1994: Symbiotical relationships in the complicated vector-pathogen system. Dokl. Akad. Nauk 338: 259-261. (In Russian.)

ALEKSEEV A.N., DUBININA H.V. 1996a: Some aspects of mite (Oppiidae) and tick (Ixodidae) pathology as a result of anthropogenic pressure. In: R. Mitchell, D.J. Horn, G.R. Needham and W.C. Welbourn (Eds.), Acarology IX. Vol. 1. Proceedings. Ohio, Biol. Survey, Columbus, Ohio, pp. 117-120.

ALEKSEEV A.N., DUBININA H.V. 1996b: Exchange of Borrelia burgdorferi between Ixodes persulcatus (Ixodidae: Acarina) sexual partners. J. Med. Entomol. 33: 351-354.

ALEKSEEV A.N., DUBININA H.V. 1997: Monitoring of the system "mites-microorganisms" as biotic components due to variation in the anthropogenic pressure. In: V.E. Sokolov, Yu.S. Reshetnikov and M.I. Shatunovsky (Eds.), Monitoring of Biological Diversity. Russian Academy of Sciences, Moscow, pp. 195-201. (In Russian.)

ALEKSEEV A.N., DUBININA H.V., ANTYKOVA L.P., DZHIVANYAN T.I., RIJPKEMA S.G.T., VERBEEK-DE
KRUIF N., CINCO M. 1998: Tick-borne borreliosis pathogen identification in Ixodes ticks (Acarina, Ixodidae) collected in St. Petersburg and Kaliningrad Baltic Regions of Russia. J. Med. Entomol. 35: 136-142.

ARTHUR D.R. 1962: Ticks and Tick Disease. Int. series of monographs on pure and appl. biol. Vol. 9. Pergamon Press, Oxford, $413 \mathrm{pp}$.

BABENKO L.V. 1985: Seasonal activity and duration of active life. In: N.A. Filippova (Ed.), Taiga Tick Ixodes persulcatus Schulze (Acarina, Ixodidae). Morphology, Systematics, Ecology, Medical Importance. Izdatelstvo "Nauka", Leningrad, pp. 219-232.

BABENKO L.V., ARUMOVA E.A., LEONOVICH S.A. 1985: Behaviour of unfed individuals. In: N.A. Filippova (Ed.), Taiga Tick Ixodes persulcatus Schulze (Acarina, Ixodidae). Morphology, Systematics, Ecology, Medical Importance. Izdatelstvo "Nauka", Leningrad, pp. 238-245.

BROWNING T.O. 1976: The aggregation of questing ticks, Rhipicephalus pulchellus, on glass stems, with observations on R. appendiculatus. Physiol. Entomol. 1: 107-114.

FILIPPOVA N.A. 1977: Ixodid Ticks. Subfamily Ixodinae. Fauna of the USSR. Arachnida. Vol. 4, No. 4. Izdatelstvo "Nauka", Leningrad, 396 pp. (In Russian.)

JENSEN P.M. 1998: Seasonal and geographical variations in the abundance of Ixodes ricinus and Lyme borreliosis transmission in Denmark. PhD Dissertation. The Royal Veterinary and Agricultural University, Copenhagen, 208 pp.

KOVALEVSKII Y.V., KORENBERG E.I. 1995: Differences in Borrelia infections in adult Ixodes persulcatus and Ixodes ricinus ticks (Acari: Ixodidae) in populations of north-western Russia. Exp. Appl. Acarol. 19: 19-29. 
LEES A.D., MILNE A. 1951: The seasonal and diurnal activities of individual sheep ticks (Ixodes ricinus L.). Parasitology 41: 189-208.

LEFCORT H., DURDEN L.A. 1996: The effect of infection with Lyme disease spirochetes (Borrelia burgdorferi) on the phototaxis, activity, and questing height of the tick vector Ixodes scapularis. Parasitology 113: 97-103.

Received 4 March 1999
McLEOD J. 1935: Ixodes ricinus in relation to its physical environment. I. The influence of climate on development. Parasitology 25: 123-144.

OKULOVA N.M. 1978: The vertical and horizontal movement of Ixodidae ticks in the forest in depending from the temperature and air humidity. Ecologiya 2: 4448. (In Russian.)

WILKINSON L. 1990: SYSTAT: The System for Statistics. SYSTAT, Evanson, IL., 255 pp.

Accepted 22 December 1999 